\title{
Localized Instantaneous Dose Rates from Inhaled Particles of ${ }^{239} \mathrm{Pu}$
}

\author{
Lucas Hetrick ${ }^{1, *}$, John Klumpp ${ }^{1}$, Deepesh Poudel $^{1}$ \\ ${ }^{1}$ Radiation Protection Division, Los Alamos National Laboratory, Los Alamos, NM
}

\section{Introduction}

Inhalation of plutonium, specifically ${ }^{239} \mathrm{Pu}$, is a topic of importance at nuclear weapons laboratories such as Los Alamos National Laboratory. The stochastic risk resulting from an inhalation event is represented by the 50-year CED expected to result from the intake, which is calculated by multiplying the activity which was inhaled by the corresponding ICRP-supplied dose coefficients. However, estimating the localized dose to lung tissue from inhaled ${ }^{239} \mathrm{Pu}$ is a more challenging task. Inhaled particles are known to deposit heterogeneously throughout the lung with particles deposited in the upper airway being swept away until they are swallowed and incorporated into the gastrointestinal tract, while particles in the lower airway tend to be less mobile. Particles that remain in the airway for extended periods of time may result in significant dose to the respiratory tract. However, because the particles are deposited heterogeneously, it is inaccurate to calculate the dose to the lung as if the particles were deposited homogenously, or to average the dose over the entire lung volume. This is especially true for alpha-emitters such as ${ }^{239} \mathrm{Pu}$, where the dose from a given particle is absorbed locally.

It is thought that the carcinogenic effects from a hot particle are less significant than that from a uniform exposure [1,2]; but literature says very little about the deterministic effects of hot particles in the lungs. For example, the National Council on Radiation Protection and Measurements (NCRP) has published limits for hot particle exposure to the lungs [3]. However, the effects of highly localized dose such as from an alpha-emitting "hot particle" are not discussed. A recent study [4] published dose rates for alpha-, beta- and gammaemitting hot particles in the lungs of rabbits. However, the resolution of this study was not sufficient to capture the local dose distribution from alpha emitters. It also does not consider that the dose distribution from alpha emitters will be different in different regions of the respiratory tract, each of which has substantially different dimensions.

This work calculates the localized dose to lung tissues from a single particle of ${ }^{239} \mathrm{Pu}$ deposited in various regions of the respiratory tract. These doses might be added and combined to predict deterministic effects in a situation in which an aerosol is inhaled, and thus to set better limits for hot particle exposures to the lungs. 


\section{Materials and Methods}

Localized dose calculations were performed using version 6.2 of the Monte Carlo NParticle radiation transport code [5] with a simplified model of an adult human airway. The model was composed of a cylinder of air surrounded by a concentric cylinder of tissue. Calculations were performed using the dimensions for regions of the lower airway $(\mathrm{BB}, \mathrm{bb}$, and AI) of an adult male as specified by ICRP Publication 66 [6]. In each case, a particle was embedded half-way into the tissue, such that one hemisphere was entirely embedded in lung tissue, while the other hemisphere was entirely exposed to the air pathway.

The dose rate from the embedded ${ }^{239} \mathrm{Pu}$ hot particle was calculated at three areas of interest for hot particles ranging from $1-100 \mu \mathrm{m}$ in increments of $10 \mu \mathrm{m} .1,10$, and $100 \mathrm{~nm}$ particles were also simulated. The first area of interest was the tissue that surrounded the hot particle. The second area of interest was located at the boundary of the airway and the tissue surrounding the particle. The third area of interest was the tissue across the airway from the hot particle. All the material compositions used in the models were taken from the Compendium of Material Composition Data for Radiation Transport Modeling [7].

\section{Discussion}

It is of interest to examine what, if any, insights this study may provide into a single particle's contribution to the induction of deterministic effects. The alpha particles from ${ }^{239} \mathrm{Pu}$ have a short range in tissue, and an even shorter range in plutonium. Although the volume irradiated by a single plutonium particle is not sufficient to result in observable deterministic effects, the cumulative volume irradiated by many plutonium particles can cause cell morbidity and mortality. While the irradiated volume differs depending on particle size, the dose rate is such that the irradiated volume would be killed in a matter of days. It is plausible that most of the alpha energy emitted by a low-solubility particle would be 'wasted' on dead tissue, which would act like shielding against healthy tissue, while mobile particles might have a greater ability to induce deterministic effects than stationary particles. This implies that particles of ${ }^{238} \mathrm{Pu}$, which are known to break up and transport themselves around the airway due to their decay energy [8], may be more harmful per unit of activity than ${ }^{239} \mathrm{Pu}$. This hypothesis could partially explain the anomaly observed in a canine study that experienced a higher than expected occurrence of pulmonary fibrosis from inhaled ${ }^{238} \mathrm{PuO}_{2}[9]$.

\section{References}

1. Coggle J, Lambert B, Moores S. Env health persp. 70; 261; 1986.

2. Lang S, Servomaa K, Kosma VM, Rytömaa T. Env health persp. 103.10:920; 1995.

3. National Council on Radiation Protection and Measurements. Report No 130 (1999)

4. Caffrey E, Johansen M, Caffrey J, Higley K. Health Physics 112.6: 526-532; 2017

5. Werner CJ, et al. Los Alamos National Laboratory. Report LA-UR-18-20808 (2018)

6. ICRP Publication 66 (1994)

7. McConn RJ, Gesh CJ, Pagh RT, Rucker RA, Williams III R. PNNL. (2011)

8. Mewhinney JA, Diel JH. Health Phys 45: 39-60; 1983.

9. Muggenburg BA, Guilmette RA, Mewhinney JA, Gillett NA, Mauderly JL, Griffith WC, Diel JH, Scott BR, Hahn FF, Boecker BB. Radiat Res 145:361-381; 1996. 